\title{
Maternidade Adolescente: A Matriz de Apoio e o Contexto de Depressão Pós-Parto
}

\author{
Giana Bitencourt Frizzo ${ }^{1}$, Letícia Wilke Franco Martins ${ }^{1, *}$, Eduarda Xavier de Lima e Silva ${ }^{1}$, \\ Cesar Augusto Piccinini ${ }^{1}, \&$ Angela Maria Polgati Diehl ${ }^{2}$ \\ ${ }^{1}$ Universidade Federal do Rio Grande do Sul, Porto Alegre, RS, Brasil \\ ${ }^{2}$ Hospital Materno Infantil Presidente Vargas, Porto Alegre, RS, Brasil
}

\begin{abstract}
RESUMO - Este estudo investigou as principais figuras de apoio referidas pelas mães adolescentes, evidenciando as possíveis funções atribuídas a essas figuras e as diferenças entre mães com e sem indicadores de depressão, de acordo com a Escala de Depressão Pós-parto de Edimburgo (EPDS). Participaram do estudo oito mães adolescentes, quatro apresentavam indicadores de depressão e quatro não. Análise de conteúdo das entrevistas revelou que as mães com indicadores citaram menos figuras de apoio do que as sem indicadores, seja porque a depressão possa ter afetado a percepção materna quanto ao apoio recebido, seja porque sua matriz de apoio mostrou-se insuficiente nesse contexto. $\mathrm{O}$ fato das participantes estarem vivenciando a adolescência concomitantemente à maternidade pode potencializar as ambivalências características dessas etapas desenvolvimentais.
\end{abstract}

PALAVRAS-CHAVE: depressão pós-parto, gravidez na adolescência, apoio social

\section{Teenage Motherhood: Support Systems in the Context of Postpartum Depression}

\begin{abstract}
The present study investigated the main figures in the support system of teenage mothers, showing their possible roles and the differences between mothers with and without indicators of depression according to the Edinburgh Postnatal Depression Scale (EPDS). Eight teenage mothers participated in the study, four with indicators of depression and four without. Interview content analysis revealed that mothers with the indicators mentioned fewer supportive figures than the others, either because depression may have affected the maternal perception of the mother's support system or because support for the mother was insufficient. The fact that the participants were experiencing adolescence concurrently with motherhood could possibly heighten the ambivalences of these developmental stages.
\end{abstract}

KEYWORDS: postpartum depression, teenage pregnancy, social support

A adolescência é uma fase do ciclo vital que pode ser compreendida como um momento em que há uma dicotomia entre questões de identidade e confusão de identidade (Erikson, 1998). A identidade seria fruto da afirmação e/ ou repúdio das identificações da infância e, ao mesmo tempo, compreenderia a dimensão social e o modo como o adolescente se reconhece enquanto indivíduo (Erikson, 1998). Nessa mesma perspectiva, o adolescente, que está se estruturando psiquicamente para acompanhar as mudanças corporais e psíquicas oriundas da adolescência e do processo de maturação, está num movimento de distanciar-se da família e de seus objetos internos infantis, a fim de ingressar no mundo adulto (Erikson, 1998, Knobel, 1981; Blos, 1996). Também é característica da adolescência o desenvolvimento da sexualidade (saindo do autoerotismo para práticas de genitalidade) (Knobel, 1981). Portanto, o adolescente e o adulto passam a se assemelhar sexualmente, uma vez que o fim sexual já pode ser o mesmo (prazer e procriação). Assim, pode-se entender que o uso da genitalidade para a procriação causará uma modificação importante no processo de conquista da identidade adulta.

*E-mail: leticiawfranco@gmail.com

- Submetido: 29/09/2015; Revisado: 07/06/2016; Aceito: 07/12/2016. 
Quando a gestação acontece na adolescência, concomitantemente a esse processo de independência psicológica dos pais, atravessa-se a tarefa do ser mãe e uma possível relação com um cônjuge. Dessa forma, surgem possíveis responsabilidades, específicas do processo de adultez, o que gera uma sobreposição de tarefas (Carter \& Mcgoldrick, 1995; Freitas, 2013; Levandowski, Piccinini, \& Lopes, 2009; Martins, Frizzo, \& Diehl, 2014).

Em uma perspectiva de comparação sobre a maternidade na adolescência e na adultez, o estudo de Kreutz (2001) buscou examinar os relatos sobre a experiência da maternidade em mães adolescentes e adultas e investigar possíveis diferenças na interação mãe-bebê. Participaram do estudo nove mães adolescentes, com idade entre $14 \mathrm{e}$ 19 anos e 10 mães adultas, com idade entre 20 e 35 anos. Os resultados obtidos ilustram algumas particularidades das mães adolescentes em comparação às mães adultas na intensidade do sofrimento provinda da adaptação ao processo da maternidade, mas sem muitas diferenças no relato da competência em ser mãe. Quanto aos achados do quesito interação mãe-bebê, o estudo sugeriu que a maternidade na adolescência não significa, necessariamente, um prejuízo na responsividade materna. Uma jovem mãe que tenha apoio social adequado pode assumir a maternidade e desenvolver uma interação mãe- bebê positiva, contribuindo para um bom desenvolvimento de sua criança (Kreutz, 2001).

A literatura enfoca a relevância das figuras de apoio no contexto da maternidade no período pré-natal e pós-natal (Frizzo, Kahl, \& Oliveira, 2005; Levandowski, Barth, Munhós, Rödde, \& Wendland, 2012). A existência dessa rede de apoio também se evidencia como fator protetor para sintomatologia depressiva (Arrais, Mourão, \& Fragalle, 2014; Baptista, Baptista, \& Torres, 2006; Bos, et al., 2013; Fonseca, Silva, \& Otta, 2010; Frizzo \& Piccinini, 2005; Goodman, 2004; Kim, Connolly, \& Tamim, 2014; Nunes \& Phipps, 2013; Prochnow \& Lopes, 2007; Thiengo, Santos, Mason, Abelha, \& Lovisi, 2011).

Stern (1997) já ressaltava a importância da matriz de apoio frente a essa nova organização psíquica que surge com o ser mãe, a Constelação da maternidade. Com a experiência da maternidade, a mãe entraria numa organização psíquica temporária, na qual se voltaria para uma nova tríade psíquica - mãe da mãe/mãe/bebê - ao invés da tríade edípica mãe/pai/bebê. Nesse novo eixo organizador da Constelação da maternidade, surgem quatro temas norteadores: o Tema vida-crescimento - a preocupação da mãe se detém na manutenção da vida da criança e o prover de suas necessidades para um bom desenvolvimento; o Tema do relacionar-se primário- a preocupação da mãe centra-se na capacidade de envolvimento emocional com seu bebê e o prover de um desenvolvimento psíquico a ele; o Tema da matriz de apoio - preocupação da mãe em recrutar e permitir sistemas de apoio para que ela execute de forma adequada o Tema vida- crescimento e o Tema do relacionar-se primário e o Tema da reorganização da identidade - a preocupação da mãe se detém na sua possível capacidade de transformar sua identidade própria para permitir e facilitar a maternidade.

Stern (1997), quando descreveu o tema da matriz de apoio, sugeriu que, tradicionalmente, a mãe deveria contar com uma rede maternal protetora de apoio, ou seja, com figuras de identificação femininas no cuidado, como sua própria mãe, tias e irmãs experientes. No entanto, também ressaltou a importância de avaliar o apoio do marido, que foi assumindo o mesmo tipo de apoio que o das figuras femininas com o passar do tempo, principalmente pelas mudanças socioculturais do papel da mulher, como, por exemplo, de desejar seguir sua carreira profissional. Assim, a ajuda concedida pelo marido visa facilitar a volta da esposa ao trabalho, além de ilustrar a capacidade de negociação do casal frente a essas mudanças nos papéis (Stern, 1997). Além disso, esse autor destacou duas possíveis funções atribuídas à matriz de apoio: apoio físico e apoio psicológico/instrumental. O apoio físico garantiria a proteção física da mãe, provendo suas necessidades e afastando-a das obrigações da realidade externa, para que ela possa dedicar-se ao bebê. O apoio psicológico/instrumental teria a função de instrução, além de fazer com que a mãe se sinta acompanhada e valorizada.

Um estudo que investigou a Constelação da maternidade em gestantes adolescentes (Martins et al., 2014) encontrou que a formação da matriz de apoio por elas é muito semelhante ao modo como ocorre com mães e gestantes adultas, descrito pela literatura. Assim como descrevia Stern (1997), os resultados mostraram que figuras femininas mais experientes na maternidade se sobressaíam, mas que também houve a entrada do marido/namorado nessa rede, assumindo, inclusive, um papel de apoio emocional à gestante adolescente. Além disso, se evidenciou a importância do novo avô, pai da adolescente, como importante figura de apoio durante a gestação (Martins et al., 2014).

Bowlby (1989), nessa mesma direção, enfatizou que o cuidado de um bebê não é tarefa de uma única pessoa e, para que essa tarefa seja bem feita, não levando o cuidador da criança à exaustão, se faz necessária uma grande assistência. Assim, se a mãe tem de cumprir essa tarefa árdua de cuidado, necessitaria de ajuda não só nos cuidados com o bebê, mas também nas atividades domésticas. Esse suporte, tanto prático, quanto emocional, fornece à mãe uma base segura para lidar com eventos estressantes, no caso, o processo de construção da maternidade em si.

Uma revisão de estudos teóricos e empíricos que relacionam apoio social e maternidade, feita por Rapoport e Piccinini (2006), evidenciou que as mães respondem à tarefa da maternidade de acordo com características pessoais, assim como com a capacidade de solicitar e aceitar o apoio de outras pessoas. De acordo com os autores, a literatura tem mostrado que a disponibilidade de uma rede de apoio social favorece a responsividade materna, trazendo benefícios para mãe, para o seu bebê e para o casal. A percepção e a forma como os indivíduos vão receber, dar, 
aceitar ou rejeitar o apoio social é dependente da cultura, do nível socioeconômico e das diferenças étnicas, mas, independentemente dessas variações, é fato que a transição da maternidade é um período complexo e que o apoio social é de fundamental importância (Rapoport \& Piccinini, 2006).

Dada a importância do apoio social, um estudo de Piccinini, Rapoport, Levandowski e Voigt (2002) procurou investigar o apoio recebido por mães adolescentes e adultas desde a gestação até o terceiro mês de vida do bebê. Os resultados mostraram que as mães adolescentes solicitavam mais apoio de familiares e outras pessoas, enquanto que as adultas tenderam a solicitar menos apoio. Além desses achados, o estudo reforça a importância do apoio social, em especial às mães adolescentes, em função das particularidades vindas dessa fase desenvolvimental.

Em relação às figuras de apoio, no contexto da maternidade em geral, as mais destacadas na literatura são a própria mãe e o companheiro. A própria mãe aparece como uma das mais importantes (Bowlby, 1989; Lewandowski et al., 2012; Martins et al., 2014; Moreira \& Sarriera, 2008; Piccinini et al., 2002; Prochnow \& Lopes, 2007; Schwartz, Vieira, \& Geib, 2011; Stern, 1997; Toomey, UmañaTaylor, Jahromi, \& Updegraff, 2013), já que colabora com sua experiência no cuidado e no modelo e formação da identidade materna. O companheiro é reconhecido por, além de exercer um papel protetor no desenvolvimento infantil (Letourneau, Stewart, \& Barnfather, 2004), ser fator protetor no contexto da depressão pós-parto (Decastro, HinojosaAyala, \& Hernandez-Prado, 2011; Frizzo \& Piccinini, 2005).

Pensando mais especificamente no apoio às mães adolescentes, alguns estudos (Moreira \& Sarriera, 2008; Schwartz et al., 2011) mostraram que as figuras de apoio mais citadas pelas mães adolescentes são sua própria mãe e o companheiro, corroborando os achados de estudos com mães adultas. Mesmo quando as mães adolescentes relataram contar com uma rede de apoio pequena, há uma percepção positiva desse apoio (Moreira \& Sarriera, 2008).

Rapoport e Piccinini (2011) destacaram a experiência da maternidade como um momento de sentimentos ambivalentes e, com a chegada do bebê e as consequentes situações revividas pelas mães e/ou por suas características de personalidade, os sentimentos depressivos poderiam surgir. No estudo em questão, no qual participaram 39 primíparas adultas, as mães relataram sentimentos e dificuldades da experiência do ser mãe, como desespero, cansaço, medo e falta de paciência, mas consideraram seus maridos, mães e sogras como uma ajuda nos períodos mais difíceis. $\mathrm{O}$ apoio não anulou as experiências negativas, mas os autores atentaram para a possibilidade dessas terem sido amenizadas, fazendo com que as mães vivenciassem a experiência da maternidade de uma forma mais positiva.

Nessa mesma perspectiva, os resultados de Konradt et al. (2011) evidenciaram relação entre a percepção da falta de suporte social na gravidez e a ocorrência de depressão da mãe no período pós-parto. Tais achados corroboram os de
Schwengber e Piccinini (2005), que também evidenciaram que as mães com indicadores de depressão apresentaram mais impressões e sentimentos negativos em relação a seus bebês, menos satisfação quanto ao desempenho do papel materno e quanto ao apoio recebido do companheiro e demais fontes.

Segundo o Manual Diagnóstico e Estatístico de Transtornos Mentais $5^{\text {a }}$ Edição (DSM 5; American Psychiatric Association [APA], 2013), a depressão pós-parto, agora inclusa nos Transtornos Depressivos, enquadra-se como um especificador do Transtorno Depressivo Maior, compreendendo o período gestacional e as quatro semanas iniciais após o parto. Entre os sintomas comuns, estão os sentimentos de inutilidade ou culpa excessiva, que podem ser delirantes, acentuada diminuição do interesse ou prazer. Ainda, segundo o Manual, $50 \%$ dos episódios depressivos maiores no "pós-parto" começam antes do parto propriamente dito e, por isso, esses são designados coletivamente como episódios no periparto (APA, 2013). Embora o DSM 5 abranja o período da gestação materna e as semanas iniciais após o parto para o diagnóstico de depressão pós-parto, a literatura também refere que os sintomas depressivos podem surgir em algum outro momento no primeiro ano de vida do bebê (Goodman, 2004; Klaus, Kennell, \& Klaus, 2000; Nonacs \& Cohen, 2005).

A Escala de Depressão Pós-Parto de Edimburgo (EPDS; Cox, Holden, \& Sagovsky, 1987, validada no Brasil por Santos et al., 2007) é um dos instrumentos de triagem para identificar indícios de depressão no puerpério. A literatura aponta a importância dessa escala, que conta com propriedades psicométricas adequadas, além de ser uma importante ferramenta para triagem, na medida em que discrimina de forma consistente o acometimento pela depressão pós-parto (Malloy-Diniz, Schlottfeldt, Figueira, Neves, \& Corrêa, 2010). O uso da Escala tem se dado em vários contextos como, por exemplo, em um estudo feito em Brasília, para avaliar a presença/intensidade dos sintomas depressivos no período posterior a uma intervenção em grupo, o Pré-Natal Psicológico (PNP). Os dados mostraram o potencial preventivo do programa de PNP para a depressão pós-parto, já que houve uma ausência de depressão, segundo a Escala, nas gestantes acompanhadas no grupo-intervenção, participantes do grupo e presença de depressão em duas das puérperas do grupo-controle, não participantes da intervenção (Arrais et al., 2014).

Outro estudo brasileiro, realizado em Natal (RN), fez uso da Escala a fim de investigar a percepção do apoio social e a prevalência de sintomas depressivos em mães de recémnascidos prematuros hospitalizados. A pontuação 11/12 foi utilizada neste estudo como indicativo de altos índices de sintomas de depressão. Os resultados indicaram uma associação negativa do apoio social percebido a sintomas depressivos (Dantas, Araújo, Paulino, \& Maia, 2012).

No contexto internacional, a Escala também tem se difundido, como num estudo realizado nos Estados Unidos, 
que teve como objetivo investigar o relacionamento de mulheres grávidas, vítimas de violência interpessoal, com suas próprias mães e outros adultos de referência e, com isso, examinar o impacto dessas relações na depressão perinatal. Nesse estudo, a partir da pontuação de 13 pontos na EPDS, foi considerado que os sintomas depressivos estavam associados com a depressão propriamente dita. Os resultados indicaram que as mães que perceberam relações positivas com suas mães ou outros adultos de referência obtiveram menores sintomas depressivos. Os dados foram estatisticamente significativos (Bhandari et al., 2012).

Tendo em vista essa questão, o estudo de Prochnow e Lopes (2007) buscou investigar a relação da mãe em situação de depressão com suas figuras femininas de apoio. Participaram sete mães adultas com indicadores de depressão, avaliadas pelo Inventário Beck de Depressão (BDI; Beck \& Steer, 1993) e por uma entrevista diagnóstica. Os achados apontaram que as mães deprimidas puderam contar com figuras de apoio que serviram como modelo de identificação, além de colaborarem para um estado de alívio do sentimento de "estar desorientada", fornecendo proteção. Além disso, o estudo evidenciou a necessidade demonstrada pelas mães de serem amparadas e protegidas, não parecendo capazes de realizar as tarefas do cotidiano e cuidar do bebê. Dessa forma, as figuras femininas acabaram por fazer uma maternagem para as mães, tanto física, quanto emocional, mas chamou atenção a delegação dos cuidados do bebê para essas figuras nos casos analisados.

Pensando na depressão em mães adolescentes e adultas, um estudo de corte retrospectivo, feito de 2004 a 2008, teve como objetivo investigar possíveis diferenças entre fatores de risco para depressão pós-parto nesses dois grupos, contando com 6959 participantes (Nunes \& Phipps, 2013). Os resultados apontaram que, no período pós-parto, tanto as mães adolescentes, quanto as adultas jovens eram mais propensas a relatar estarem se sentindo deprimidas ou sem esperança, sentindo pouco interesse ou pouco prazer. $\mathrm{O}$ estudo evidenciou que a presença de apoio social, em geral, reduziu as chances das mães relatarem os sintomas de depressão pós-parto, identificando a falta de apoio como o principal fator de risco da depressão pós-parto entre as mães adolescentes e entre as mães adultas (Nunes \& Phipps, 2013).
Da mesma forma, o estudo de Airosa e Silva (2013), que teve como objetivo analisar uma possível associação entre suporte social, sintomatologia depressiva, ansiosa e estresse e a vinculação mãe-bebê em 100 participantes brasileiras, das quais 50 se encontram no período gestacional e as restantes na fase do pós-parto, reforçou que quanto maior a satisfação de apoio social, menor seriam os sintomas apontados.

O estudo de Kim et al (2014) examinou e comparou os efeitos do apoio social recebido antes e depois da gravidez em adolescentes e mulheres canadenses com depressão pósparto, encontrando que tanto as mães adolescentes, quanto as mães adultas eram cerca de cinco vezes mais propensas a apresentar indicadores de depressão pós-parto, segundo o EPDS, se elas não haviam recebido apoio mínimo ou nenhum apoio após o nascimento do bebê, concluindo, dessa forma, que ter apoio social reduz os riscos de desenvolver uma depressão pós-parto independentemente da idade da mãe.

Nessa mesma perspectiva, um estudo realizado no México (Decastro et al., 2011) com 298 mães, adolescentes e adultas, teve como objetivo explorar fatores de risco e proteção associados com a depressão pós-parto em mães adolescentes através da comparação entre ambos os grupos. Como resultado, foi sugerido que o apoio social tem benefícios ainda maiores em mães mais jovens e que vivem com o parceiro/cônjuge. No entanto, uma análise mais aprofundada por grupo revelou que esse contato com o companheiro foi significativo apenas para mães adultas. Esse resultado corroborou outros estudos que salientaram o apoio dos parceiros como particularmente relevante para as mães adultas, enquanto que para as mães adolescentes solteiras, a confiança viria principalmente das próprias famílias, tanto para ajuda financeira, como para apoio emocional (Decastro et al., 2011).

Prochnow e Lopes (2007) ressaltaram a precariedade dos estudos dedicados ao apoio e à importância do suporte fornecido às mães no contexto da depressão, já que os estudos têm apontado a falta de apoio social como um fator de risco para o desenvolvimento de tal patologia. Nesse sentido, o objetivo do presente estudo foi investigar as principais figuras de apoio referidas pelas mães adolescentes, evidenciando as possíveis funções atribuídas a essas figuras e as diferenças entre mães com e sem indicadores de depressão, de acordo com a EPDS.

\section{MÉTODO}

\section{Delineamento e Procedimentos}

O artigo trata-se de um estudo transversal e qualitativo, em que foi utilizado um delineamento de estudo de casos múltiplos, cruzados com ênfase às particularidades e semelhanças (Yin, 2001), com o intuito de investigar a percepção de apoio de mães adolescentes com e sem indicadores de depressão, em especial ressaltando as principais figuras na matriz de apoio e as funções atribuídas a elas.

Primeiramente, as gestantes foram convidadas a participar do estudo e, então, esclarecidas através da leitura do Termo de Consentimento Livre e Esclarecido (Núcleo de Infância e Família da Universidade Federal do Rio 
Grande do Sul [NUDIF/UFRGS], 2008a), sendo assinado pela gestante e pelo adulto responsável. As gestantes responderam individualmente às entrevistas previstas para o terceiro trimestre da gravidez. Quando o bebê completou o $3^{\circ}$ mês de vida, as mães foram novamente contatadas e responderam individualmente à Entrevista sobre a maternidade e sobre o desenvolvimento do bebê - terceiro mês de vida do bebê (NUDIF/UFRGS, 2009c), a EPDS (Cox et al., 1987, validada no Brasil por Santos et al., 2007) foi utilizada para rastrear possíveis indicadores de depressão no puerpério.

Para o presente estudo, foram analisadas a Entrevista de dados sócio demográficos (NUDIF/UFRGS, 2008b, adaptada de PAIGA-HMIPV), a Entrevista sobre a maternidade e sobre o desenvolvimento do bebê - terceiro mês de vida do bebê (NUDIF/UFRGS, 2009c) e a Escala de Depressão Pós-parto de Edimburgo - EPDS (Cox, Holden, \& Sagovsky, 1987, validada no Brasil por Santos et al., 2007).

\section{Participantes}

Participaram do estudo oito mães adolescentes primíparas, com idade média de 17 anos $(D P=0,83)$, sendo quatro com indicadores ${ }^{1}$ de depressão e quatro sem indicadores, de acordo com a EPDS. Todas foram participantes do projeto Aspectos Biopsicossociais da Gravidez Adolescente: Estudo Longitudinal da Gestação ao Segundo Ano de Vida da Criança" (GRADO; NUDIF/ UFRGS, 2008). Esse estudo multicêntrico, envolvendo as cidades de Porto Alegre, Santa Maria e Rio Grande, acompanhou 180 adolescentes, desde o terceiro trimestre de sua gestação e estendendo até o vigésimo quarto mês de vida do bebê. Especificamente no centro Porto Alegre, foram acompanhadas 60 gestantes e, quando possível, seu companheiro e a avó materna do bebê também foram convidados a participar do estudo. Os critérios de inclusão para a participação no projeto longitudinal foram: que as adolescentes não apresentassem intercorrências clínicas durante a gravidez, que a gravidez não fosse fruto de abuso sexual, que não tivessem comprometimento mental e emocional e que não fossem usuárias de substâncias (álcool e/ou drogas) durante a gestação.

Para fins do presente estudo, as participantes investigadas foram as de Porto Alegre e a etapa explorada será a da Fase II do estudo - terceiro mês de vida do bebê. O critério de seleção foi feito a partir dos indicadores na

1 Refere-se a indicadores de depressão pós-parto, uma vez que somente foi utilizada a EPDS e não foi realizada entrevista clínica para confirmar diagnóstico.

2 Esse projeto contemplou quatro fases de coletas de dados: (1) terceiro trimestre da gestação; (2) 3 meses de vida do bebê; (3) 12 meses de vida do bebê e (4) 24 meses de vida do bebê. As gestantes foram selecionadas a partir do encaminhamento de hospitais públicos de Porto Alegre e de unidades básicas de saúde e tiveram o Termo de Consentimento Livre e Esclarecido assinado pelo responsável.
EPDS, contemplando todas as mães participantes da Fase II que apresentaram indicadores de depressão que foram, posteriormente, pareadas com mães sem indicadores quanto ao sexo do bebê e suas respectivas idades, formando, então, dois grupos: mães com indicadores de depressão (MCI3) e mães sem indicadores de depressão (MSI) (Tabela 1).

Tabela 1

Mães participantes do estudo com indicadores (MCI) e sem indicadores de depressão (MSI), com suas respectivas idades, escores no EPDS e sexo do bebê

\begin{tabular}{lccc}
\hline $\begin{array}{c}\text { Código } \\
\text { do caso }\end{array}$ & $\begin{array}{c}\text { Idade } \\
\text { da mãe }\end{array}$ & $\begin{array}{c}\text { Escore } \\
\text { no EPDS }\end{array}$ & $\begin{array}{c}\text { Sexo } \\
\text { do bebê }\end{array}$ \\
\hline MCI A & 18 & 25 & Masculino \\
MCI B & 17 & 11 & Masculino \\
MCI C & 16 & 22 & Masculino \\
MCI D & 16 & 18 & Feminino \\
MSI E & 18 & 1 & Masculino \\
MSI F & 17 & 4 & Masculino \\
MSI G & 17 & 4 & Masculino \\
MSI H & 16 & 3 & Feminino \\
\hline
\end{tabular}

\section{Instrumentos e materiais}

Entrevista de dados sócio demográficos (NUDIF/ UFRGS, 2008b adaptada de PAIGA-HMIPV). Esse instrumento foi utilizado para fins de levantamento sobre dados sócio-demográficos da mãe adolescente e de sua família, como a idade, escolaridade, condições de moradia, renda e questões da própria gestação.

Entrevista sobre a maternidade e sobre o desenvolvimento do bebê - Terceiro mês (NUDIF/ UFRGS, 2009c). A entrevista investiga sobre a experiência da maternidade e sobre questões referentes ao nascimento do bebê, em especial no momento do parto e sobre os três primeiros meses do bebê, focando na percepção da mãe sobre suas aquisições desenvolvimentais. Também averigua sobre o dia-a-dia da mãe com seu bebê após a saída do hospital, focando em questões como o apoio que recebeu, possíveis mudanças na relação com o cônjuge/companheiro, o incumbir-se do cuidado com o bebê e sobre a divisão dos cuidados, organização e expectativas. Também investiga a relação da mãe adolescente com sua família após o nascimento de seu filho e averigua os planos futuros da mãe.

3 A legenda MCI corresponde ao grupo Mães com indicadores de depressão, enquanto MSI, Mães sem indicadores de depressão. Nas vinhetas, a legenda do grupo estará acompanhada da letra do caso correspondente. 
Escala de Depressão Pós-parto de Edimburgo (Cox et al., 1987, validada no Brasil por Santos et al., 2007). É um instrumento de triagem que averiguará possíveis índices de depressão no puerpério. Auto-avaliativo e constituído por dez itens, o EPDS é pontuado de 0 a 3 , de acordo com a presença ou não da sintomatologia em questão, levando em conta sua intensidade. São feitos questionamentos acerca da percepção da mãe de ver o lado divertido das situações, possível culpabilidade que ela tem sobre si mesma, ansiedades e medos, sentimento de infelicidade, vontade de chorar e que a mãe tem de fazer mal a si mesma. As questões 1 e 2 são cotadas crescentemente, enquanto que da 4 questão até a 10 há uma cotação de forma inversa. Segundo o estudo de validação no Brasil, o melhor ponto de corte para rastreamento foi para escores maiores ou iguais a 10 , com sensibilidade de $82,6 \%$ (Santos et al, 2007).

\section{Considerações Éticas}

Este artigo seguiu os princípios éticos da pesquisa que dizem respeito à proteção dos direitos, bem-estar e dignidade dos participantes, como destacado pela resolução 466/12 do Conselho Nacional de Saúde. As adolescentes que demonstraram interesse em participarem da pesquisa receberam o Termo de Consentimento Livre e Esclarecido
(NUDIF, 2008c). Visto que a maioria dos participantes era menor de idade, o termo foi lido e consentido também pelo responsável legal do adolescente. O presente estudo faz parte do projeto GRADO, que foi submetido ao Comitê de Ética da UFRGS (Processo n ${ }^{\circ}$ 25000.089325/2006-58, em 07/04/2008) e pelo comitê de Ética do HMIPV (Processo no 20/08).

\section{Análise de Dados}

A análise de conteúdo das entrevistas (Laville \& Dionne, 1999) foi utilizada para investigar as percepções das mães adolescentes, com indicadores e sem indicadores de depressão, em relação à sua matriz de apoio, evidenciando as principais figuras de apoio e suas funções. Para tal, foram utilizadas todas as passagens da Entrevista sobre a maternidade e o desenvolvimento do bebê- Terceiro mês, na qual a mãe ressalta suas figuras de apoio. A matriz de apoio, no presente estudo, foi pensada a partir do terceiro tema da Constelação da maternidade (Stern, 1997): A matriz de apoio refere-se à necessidade da mãe de criar, permitir, aceitar, regular uma rede de apoio protetora, benigna, para que possa ela atender as necessidades físicas de seu bebê, permitindo assim, um bom desenvolvimento físico e o atendimento as suas necessidades emocionais, permitindo um bom desenvolvimento psíquico.

\section{RESULTADOS E DISCUSSÃO}

Os resultados obtidos serão apresentados em quatro categorias, formadas de acordo com as figuras de apoio mencionadas pelas mães adolescentes com e sem indicadores de depressão e serão ilustradas com os seus próprios relatos: (1) A mãe como a principal figura de apoio; (2) O companheiro como figura de apoio; (3) A sogra e outras figuras femininas de apoio; (4) O pai e outras figuras masculinas de apoio.

\section{A Mãe como a Principal Figura de Apoio}

Assim como o esperado, a partir da análise das entrevistas percebemos que, no contexto da gravidez na adolescência, todas as mães - tanto as quatro mães com indicadores de depressão, quanto as quatro mães sem indicadores- ressaltaram como principal figura da matriz de apoio a sua própria mãe. Tal achado vai ao encontro da literatura, que evidencia que a mãe como figura de apoio, em todos os contextos de maternidade, tem um papel fundamental. (Bowlby, 1989; Levandowski et al., 2012; Lopes, Prochnow \& Piccinini, 2010; Martins et al., 2014; Moreira \& Sarriera, 2008; Piccinini et al., 2002; Prochnow \& Lopes, 2007; Rapoport, 2003; Stern, 1997; Schwartz et al., 2011 Toomey et al., 2013).
A figura materna foi referida como aquela com quem a adolescente pode contar em todos os momentos, sentindo-se ajudada, valorizada e instruída, assumindo a função de um apoio psicológico/instrumental, apontado por Stern (1997) na Constelação da maternidade, mesmo no contexto de depressão:

Me ensinou (a mãe) muita coisa. Desde quando a gente descobriu que eu tava grávida, até hoje, ela sempre me apoiou em tudo, me ajuda em tudo, e... Tudo que ela diz pra mim fazer, eu faço. Mesmo às vezes eu achando que é errado, mas eu faço. Porque ela já criou quatro filhas, e eu a recém a primeira. (MCI D)

Esse achado corroborou o estudo de Schwartz et al. (2011), que, ao investigarem a percepção de mães adolescentes em relação ao apoio que receberam no período gestacional, destacaram as próprias mães/avós como supridoras de informação, devido a própria experiência de vida.

Outra possível explicação para a própria mãe ser a mais citada em ambos grupos é que, com o nascimento de uma criança e com todas as mudanças envolvidas no psiquismo dessa nova mãe, é indispensável que ela possa 
contar com uma figura feminina que lhe passe experiência e segurança (Stern, 1997). Além do auxílio propriamente dito, o apoio dessa figura experiente faz também com que a nova mãe possa se espelhar e tomá-la como um modelo de identificação, facilitando, dessa forma, o desenvolvimento da função materna (Cabral \& Levandowski, 2011a, 2011b; Golse, 2003; Martins, 2014).

Outra semelhança encontrada no estudo, atribuída como função à figura materna, é o prover de recursos, já que, nessa conjuntura, muitas mães adolescentes dependiam financeiramente de sua família de origem e no cuidado da casa no geral, assumindo uma dimensão de apoio físico, possibilitando, assim, que a mãe se dedicasse ao bebê, uma vez que a matriz de apoio tem também essa função dentro da Constelação da maternidade (Stern, 1997). Isso se evidenciou nas falas de mães adolescentes com e sem indicadores de depressão:

Ah, a minha mãe fazia tudo pra mim, porque eu não podia levantar da cama, então minha mãe fazia comida, lavava roupa, lavava louça (...). (MCI B)

(...) eu não tenho condições de dar, hoje em dia, tipo, comida, então quem tá sustentando ele é a minha mãe e eu to estudando ainda, então tá, daqui a cinco anos eu vou me formar, ele já vai tá na escola, como é que eu vou pagar a escola pra ele se eu vou estar recém formada na faculdade, só que né, do jeito que a gente tá agora, a gente vai dando jeito né. (MSI G)

Esses resultados vão ao encontro dos achados de Piccinini et al. (2002), que, comparando mães adultas e mães adolescentes, evidenciou tanto um apoio informacional, quanto um apoio financeiro maior para as adolescentes. Segundo os autores, tal achado pode ser explicado por uma possível falta de planejamento da gravidez e pela incapacidade das adolescentes se sustentarem como casal e família.

Por outro lado, cabe esclarecer que nem todas as avós, sejam elas as mães da própria mãe ou as suas sogras, são vistas como figuras de apoio e proteção. Ao contrário disso, quando não há uma boa relação, essas figuras são apontadas como fatores de risco para a depressão pós-parto (Arrais et al., 2014). Portanto, não basta haver uma proximidade física, tendo a mãe ou a sogra por perto, mas sim é necessário que haja um reconhecimento por parte dessa mãe com relação a essas figuras e, assim, abra-se a possibilidade para um bom relacionamento.

A literatura aponta que a falta de uma relação positiva e de suporte mãe-filha pode contribuir para maiores dificuldades nas futuras habilidades parentais da nova mãe. Pode ser que a dificuldade em acessar modelos de referência, em função de uma certa carência desses em sua própria infância, esteja relacionada à promoção do desenvolvimento infantil e, ainda, associados a um não exemplo do que constitui um relacionamento amoroso com outro adulto, essas mães podem ser duplamente desafiadas em seus papeis parentais (Bhandari et al., 2012). Entretanto, no caso em que não há a própria mãe como referência de apoio, se fazem interessantes as fontes alternativas de apoio (Bhandari et al., 2012), ou seja, as figuras que estejam disponíveis para auxiliar nesse momento, já que o mais importante é que a recém mãe tenha com quem contar e, assim, tenha sua saúde emocional assegurada.

\section{O Companheiro como Figura de Apoio}

Das oito participantes, duas mães, uma com e outra sem indicadores de depressão, não contaram com a presença de um companheiro no pré-natal e pós-parto. Nas falas das seis participantes restantes (três mães com indicadores e três mães sem indicadores), o companheiro apareceu como uma das figuras de apoio mais reconhecidas pelas mães, tanto com indicadores de depressão, quanto sem indicadores, indo ao encontro da literatura (Bowlby, 1989; Moreira \& Sarrieira, 2008; Rapoport et al., 2006; Schwartz et al., 2011), já que nos dias de hoje o homem participa de praticamente todas as tarefas de cuidados, concedendo tanto apoio psicológico, quanto apoio físico (Stern, 1997).

No contexto da gravidez adolescente, a figura do companheiro surge como aquela que divide os cuidados do bebê com a nova mãe, assumindo uma dimensão de apoio emocional (Martins et al., 2014; Stern, 1997). Contudo, independentemente dos indicadores de depressão, também foi identificado, a partir das falas das mães, uma certa insegurança de seus companheiros frente às novas tarefas para suprir as necessidades dos bebês:

Ah, ele me ajudou a cuidar dela, a trocar ela. A... Tudo, né, menos dar banho, que eu acho que ele também tinha medo. Eu falava assim 'Dá banho nela' e ele 'Não, dá banho tu, ou dá a tua mãe'. Mas acho que ele tinha medo, só que ele falava que não tinha, né. (MCI D)

[...] ele me ajuda bastante, ele troca, ele faz tudo, menos dar banho. Banho, ele não dá, mas ele ajuda a trocar, a maioria da parte do tempo é ele que troca, mas banho, assim, eu que faço, ele fica com ela a maior parte do tempo pra mim poder fazer as coisas dentro de casa, então a gente se divide cuidando dela. (MSI H)

Em se tratando dessa insegurança dos companheiros ressaltada no discurso materno, é relevante considerarmos que essas falas também podem refletir a ambivalência vivida pelos adolescentes, devido à sobreposição de tarefas - adolescência e parentalidade (Carter \& Mcgoldrick, 1995; Freitas, 2013; Levandowski et al, 2009; Martins et al., 2014).

Os companheiros também assumiram a dimensão de um apoio físico (Stern, 1997) cuidando do entorno, em especial das tarefas domésticas, para que a mãe conseguisse se voltar mais para o novo bebê: 
[...] o meu marido também lavava as roupinhas dele e me ajudava na hora do banho, pra mim, que eu tinha que fazer banho de assento e um monte de coisa. (MCI B)

Apoiou, que a casa tava uma bagunça, ele (o marido) ia lá e arrumava. Então eu ficava mais no cuidado e preocupação com o nenê e ele não tinha jeito pra pegar [...]. Varrer uma casa, que às vezes é uma coisa a mais que eu me preocupo, juntar as roupas sujas, lavar uma louça, ele me ajuda nisso dai [...]. (MSI E)

Além de ter essa função da ajuda com o entorno, com as atividades externas, Stern (1997) considerava apoio fisico o prover das necessidades vitais da mãe que se encontra nessa nova organização psíquica, que é a Constelação da maternidade, o que também foi visto no presente estudo, atrelado à divisão nos cuidados:

Quando ele tá em casa, assim, que ele não tá trabalhando, que ela acorda, ele fica com ela. Se ela recém mamou e ela não quer dormir, ele fica com ela pra mim dormir, pra mim descansar. Isso, esses apoios. Às vezes quando tá de madrugada, que eu vou mudar ela, eu peço pra ele... Às vezes quando eu to muito cansada, pra ele pegar ela na cama ou pra ele pegar a pomada, ou a fralda, assim. (MCI D)

Ele tinha medo de pegar ele, mas ajudava. Ah, pegava ele, como...Quando eu precisasse ir no banheiro, ou alguma coisa. Quando eu ia comer. (MSI F)

As percepções de apoio do companheiro não se diferiram no presente estudo, se compararmos às mães com indicadores e às mães sem indicadores de depressão. Nos dois cenários, o companheiro foi citado como aquele que aprende junto, dividindo os cuidados e assumindo um apoio emocional e ao mesmo tempo um apoio físico - cuidando tanto do externo, quanto de prover as necessidades vitais da mãe (sono, alimentação). Portanto, o pai do bebê aparece como uma figura importante, tanto emocionalmente, quanto em questões práticas no auxílio da mãe com o bebê (Cramer \& Palacio-Espasa, 1993; Stern, 1997; Winnicott, 1985).

Numa perspectiva mais atual, o companheiro seria aquele que serviria como "uma proteção, como um parachoque físico e prático, como um apoio psicológico e como um marido-homem" (Stern, 1997, p. 168), o que vai ao encontro dos achados do presente estudo. Dentro dessa perspectiva, tal resultado reforça os achados de Lopes et al. (2010), que ressaltaram que, pelo menos nas sociedades ocidentais, a participação do companheiro é de suma importância nos cuidados com o bebê, no apoio emocional, na realização das atividades domésticas e na proteção da mulher, para que ela possa se dedicar à maternidade. Interessante atentarmos para a importância desse envolvimento do pai no fornecimento de apoio à recém-mãe, já que esse pode exercer um papel protetor no desenvolvimento infantil (Letourneau et al., 2004) e no contexto da depressão pós-parto (Arrais et al., 2014; Decastro et al., 2011; Frizzo \& Piccinini, 2005). Inclusive, uma pesquisa que tinha como objetivo associar dor e depressão pós-parto, encontrou associação entre dor moderada a forte com não ter bom convívio com companheiro/cônjuge (Angelo et al., 2014).

\section{A Sogra e Outras Figuras Femininas de Apoio}

Esta foi uma das categorias que apresentou maiores diferenças nas percepções das mães com indicadores de depressão e sem indicadores. As mães sem indicadores de depressão referiram-se a madrinhas, sogra, cunhada, irmã, vizinha e amiga:

A minha cunhada, a minha sogra, a minha mãe, as minhas irmãs, tudo vieram, sempre tinha uma pessoa ali do meu lado. [...] ao invés delas quererem pegar ela, pra mim fazer as coisas, elas faziam pra mim, esquentavam água, lavavam as roupas, as coisas assim. (MSI H)

A única mãe com indicador de depressão que se referiu a outras figuras femininas de apoio enfatizou apenas uma irmã na qual podia contar:

A minha mãe, a minha irmã e a minha sogra, foi essas (figuras com quem pôde contar). Ah, elas me ensinaram ao mesmo tempo como cuida dele, o que que eu devia fazer, me ajudaram na minha casa, né, a limpar e tudo e a reparar ele também. (MCI C)

A sogra apareceu com um papel similar ao da própria mãe, assumindo também a dimensão do apoio físico (Stern, 1997): “[...]ela (sogra) perguntava, ela pedia 'quer que eu lave as tuas roupas?'. Ela ia lá, pegava as minhas roupas e me ajudava no que ela podia. Ela ia lá e fazia por mim [...]” (MSI G). Três das mães sem indicadores referiram a sogra como fonte de apoio, enquanto apenas uma das mães com indicadores fizeram essa referência. Novamente, $o$ importante é que haja reconhecimento por parte da mãe com relação às pessoas que compõem a matriz de apoio, já que, quando não há boa relação interpessoal, essas mesmas figuras são apontadas como fatores de risco para depressão pós-parto (Arrais et al., 2014).

Bowlby (1989) forneceu subsídios para pensarmos na importância de tais figuras no apoio à recém-mãe. Segundo ele, além da ajuda prática, a companhia de uma outra figura feminina tende a oferecer um suporte emocional e, em suas palavras, oferecer uma base segura. As figuras femininas de apoio poderiam ser uma fonte de auxílio para as novas mães, em especial por serem figuras experientes nos assuntos referidos à maternagem, fazendo com que elas se sentissem auxiliadas no desenvolvimento das capacidades maternas e no exercer de funções como mãe, corroborando os achados de Lopes et al. (2010). 
No presente estudo, verificou-se que as outras figuras femininas percebidas pelas mães adolescentes foram referidas pelas quatro mães sem indicadores, enquanto apenas uma mãe com indicadores fez tal referência. Todavia, não foram observadas grandes diferenças com relação à percepção da ajuda recebida. Independentemente de ter depressão ou não, as outras figuras femininas surgiram como aquelas com quem as mães podem contar, como ajudando na casa, sendo, assim, uma dimensão de apoio físico (Stern, 1997) e, ao mesmo tempo, uma figura que auxilia no modo de cuidar, propiciando segurança às mães, em uma dimensão de apoio psicológico/instrumental (Stern, 1997). Uma mãe (MSI E) inclusive referiu-se à sua amiga e comadre como um apoio financeiro, o que não apareceu nos demais casos.

Pensando nos achados do presente estudo, as mães deprimidas podem não ter citado tanto outras figuras femininas de apoio quanto as sem indicadores, por estarem muito dependentes e voltadas às suas mães, já que estão vivendo um período de significativas mudanças psíquicas vindas da adolescência, da maternidade e das dificuldades impostas pela sintomatologia depressiva. Além disso, Dantas et al (2012), ao investigarem a associação entre apoio social e sintomatologia depressiva no contexto de prematuridade e hospitalização, encontraram uma relação negativa entre essas duas dimensões, em que quanto maior o apoio percebido, menor são os sintomas depressivos e vice-versa.

Além disso, também foi encontrado que quanto melhor foi a percepção materna de seu estado geral de saúde, maior foi a pontuação na dimensão de apoio emocional por elas identificado. Esses achados parecem contribuir com os resultados aqui encontrados, na medida em que podemos entender que a saúde psíquica materna também contribui e parece repercutir na percepção de auxílio recebido ou não de sua matriz de apoio. Milgron e McCloud (1996) mostraram que as mães com depressão relataram algumas dificuldades, como o sentimento de incompetência, ligado emocionalmente ao bebê, de dependência e de isolamento social, o que poderia ser uma possível justificativa devido à diferença das referências às figuras de apoio, já que as mães deprimidas parecem contar com menos figuras.

Além disso, devemos retomar que faz parte do tema Matriz de Apoio criar, permitir, aceitar e regular uma rede protetora com figuras de apoio (Stern, 1997) e, em casos de patologia materna como a depressão, esse processo pode ficar dificultado em algumas dessas funções. Deve-se destacar que, muitas vezes, mães deprimidas apresentam sintomas como não se sentir querida e amada e culpa por dificuldades em conciliar questões do cuidado da casa, do bebê e do trabalho. Ou seja, uma desvalia intensa, que realmente dificulta sentir-se merecedora de apoio, pois pedir ajuda é sentido como mais uma confirmação de sua impossibilidade de dar conta dos cuidados de sua família (Frizzo, Prado, Linares, \& Piccinini, 2011).

\section{O Pai e Outras Figuras Masculinas de Apoio}

A referência ao pai - novo avô - e a outras figuras masculinas de apoio foram diferentes na percepção das mães com indicadores e sem indicadores de depressão. Em relação às outras figuras masculinas que não fossem seus próprios pais, as mães adolescentes com indicadores de depressão não se referiram a ninguém. Três das quatro mães adolescentes sem indicadores de depressão citaram o sogro, irmão e o padrinho da criança: "[...] eu moro com eles (com o sogro e com a sogra), então eles são mais próximos de mim em qualquer momento, pra mim ir no armazém, qualquer lugar, mercado" (MSI H).

Duas mães sem indicadores fizeram referência ao seu pai, enquanto uma única mãe com indicador de depressão o referenciou. No caso MCI B, em que a mãe tinha indicadores de depressão, o seu pai assumiu a tarefa mais voltada ao financeiro, mas mostrando preocupação com a nova mãe: "Ah, ele (o pai) me ajudou, ele comprava os remédios, sempre preocupado comigo, queria saber, o que ele podia, ele fazia" (MCI B).

Nos casos MSI H e MSI G, em que as mães não tinham indicadores de depressão, o pai - avô materno do bebê assumiu um papel de instrução junto com a própria mãe - avó materna -, sendo um aliado na divisão de cuidados:

(os pais dizem) que tem que ter cuidado, que eu não me espelhe nos outros né, que os outros fazem, eu não fazer com ela, [...] quando eu sair sozinha com ela (a bebê), quando eu vim no hospital pedir pra alguém segurar ela, a minha mãe diz que não, que não é pra mim fazer isso. (MSI H)

[...] meu pai me ajuda bastante também. [...] ah quando eu preciso, eu to com ele (o bebê) no colo e eu preciso de alguma coisa, quando eu preciso, eu to cansada e eu preciso dormir, ai o bebê tá acordado, eu deixo com ele (com o pai), tudo que precisa assim. (MSI G)

Tais achados corroboram os de Martins et al. (2014), em que gestantes adolescentes (que não possuíam indicadores de depressão) também relataram o apoio emocional fornecido por essas figuras masculinas (pai e outros homens) que não sejam o companheiro. Por sua vez, o fato das mães adolescentes com indicadores de depressão não terem citado o pai e outras figuras de apoio parece estar relacionado à dificuldade em perceber e se sentirem satisfeitas com o apoio recebido, uma vez que mães com indicadores de depressão tendem a apresentar menos satisfação com o apoio recebido do companheiro e demais fontes (Schwengber \& Piccinini, 2005), além de ter sido verificada relação entre a percepção da falta de suporte social na gravidez e a ocorrência de depressão da mãe no período pós-parto (Konradt et al, 2011).

No entato, é importante termos em vista que, para além de uma percepção distorcida com relação às suas possíveis figuras de apoio, estudos indicam que a depressão pós-parto pode estar associada, entre outros fatores, à uma rede de 
apoio social e familiar insuficiente (Arrais et al., 2014; Bos et al., 2013). Também devemos considerar que a Constelação da maternidade é composta por quatro temas inteligados, então é plausível pensar que uma boa percepção sobre a matriz de apoio pode influenciar para que a mãe tenha um bom desempenho nos demais temas, como o Tema vidacrescimento, o Tema do relacionar-se primário e o Tema da Reorganização da identidade.

\section{CONCLUSÕES E CONSIDERAÇÕES FINAIS}

O presente estudo teve como objetivo investigar as principais figuras de apoio referidas pelas mães adolescentes, evidenciando as possíveis funções atribuídas a essas figuras e as diferenças entre mães com e sem indicadores de depressão, de acordo com a EPDS. Para tanto, utilizou-se no presente estudo, o tema de matriz de apoio, terceiro tema da Constelação da maternidade (Stern, 1997), que refere-se à necessidade da mãe de criar, permitir, aceitar e regular uma rede protetora com figuras de apoio que permitam que a mãe atenda às necessidades físicas e emocionais de seu bebê.

As figuras de apoio mais citadas pelas mães com indicadores de depressão foram, respectivamente, a sua mãe, o companheiro, outras figuras femininas (madrinha/irmã), sua sogra e o seu pai, enquanto para as mães sem indicadores de depressão foram, respectivamente, a sua mãe, outras figuras femininas, companheiro, a sogra, outras figuras masculinas e o pai. Percebeu-se que independentemente da presença de indicadores de depressão ou não, as mães adolescentes acabaram reconhecendo mais a sua própria mãe como apoio do que as demais figuras.

A depressão pode, inclusive, afetar a percepção das mães adolescentes quanto ao apoio recebido, demonstrando sentimentos ambivalentes em relação ao apoio social, por exemplo, ao apoio do companheiro (Piccinini, Frizzo, Brys, \& Lopes, 2014; Schwengber \& Piccinini, 2005), resultado também encontrado no presente estudo. Porém, as mães respondem à tarefa da maternidade de acordo com características pessoais, assim como a percepção e a forma como vão receber, aceitar ou rejeitar o apoio social é dependente da cultura, do nível socioeconômico e das diferenças étnicas, mas, independentemente dessas variações, é fato que a transição para a maternidade é um período complexo e que o apoio social é de fundamental importância (Rapoport \& Piccinini, 2006).

Além de uma percepção distorcida com relação às suas possíveis figuras de apoio, estudos indicam que a depressão pós-parto pode estar associada, entre outros fatores, a uma rede de apoio social e familiar insuficiente (Arrais et al., 2014; Frizzo et al., 2011; Linares \& Campo, 2000). Todavia, esse resultado também poderia ser explicado porque as participantes do presente estudo estão na adolescência, caracterizada por ser uma fase desenvolvimental dicotômica entre questões de identidade e confusão de identidade (Erikson, 1998), além de serem mães, o que tornaria tudo ainda mais ambivalente (Levandowksi et al., 2009), independentemente de serem deprimidas ou não.

Porém, o tamanho da rede de apoio não se fez tão relevante para essas jovens, mas sim a intensidade do apoio (Moreira \& Sarriera, 2008). Dessa forma, fica a questão se as mães participantes do presente estudo, com indicadores e sem indicadores de depressão, consideravam a quantidade de apoio por diversas figuras como relevante ou se consideraram mais a intensidade no apoio recebido. No caso das mães deprimidas, talvez por sentirem dificuldade de convocarem outras pessoas para o auxílio, acabaram recrutando menos figuras para sua matriz de apoio, mas as destinando mais tarefas ou contando mais com elas do que as não deprimidas. Seria interessante, nessa perspectiva, avaliar em outros estudos a percepção da avó (do bebê), do companheiro e demais figuras de apoio, a fim de saber como se configurava a divisão dos cuidados e possíveis sobrecargas nas funções assumidas por eles.

O presente estudo corroborou a literatura, (Schwartz et al., 2011; Moreira \& Sarrieira, 2008) ao encontrar como principais figuras de apoio, respectivamente, a própria mãe e o companheiro, independentemente da presença/ ausência dos indicadores de depressão. Em relação ao apoio do companheiro, é interessante que surjam novos estudos que enfoquem o seu papel específico no contexto da depressão pós-parto, já que quando a mulher encontrase deprimida, com sentimentos de desvalia e dificuldades no relacionamento conjugal, isso pode também afetar a qualidade da relação que poderá estabelecer com seu bebê (Frizzo, Brys, Lopes, \& Piccinini, 2010). Da mesma forma, sua importância também se dá pelo fato de que o apoio do companheiro está entre os fatores de proteção com relação à depressão pós-parto (Arrais et al., 2014)

Uma das limitações do estudo se encontra no fato de que não foram averiguados os antecedentes clínicos das participantes, em especial, a história prévia de depressão. Das mulheres que desenvolvem depressão durante a gestação, grande parte apresenta precedentes de episódios depressivos e, além disso, a frequência de sintomas depressivos tende a ser maior do que o transtorno depressivo propriamente dito na população, o que poderia ser um dos motivos para a prevalência acima da média de tal sintomatologia, visualizada em muitos pesquisas com escalas de rastreamento de depressão (Thiengo et al., 2011).

Uma outra limitação seria o fato de que duas mães, uma com e outra sem indicadores de depressão, uma não contava com a presença do companheiro, o que poderia ser refletido na própria referência das mesmas em relação às suas figuras de apoio.

Uma questão que perpassa o estudo, mas que não encontrou aportes para ser respondida, foi se as mães apresentam a sintomatologia depressiva por não conseguirem 
pedir auxílio e, dessa forma, conseguir o apoio necessário ou se pelo fato delas não poderem contar com muitas figuras de apoio e previamente desenvolveram tal sintomatologia. Nessa mesma perspectiva, na revisão feita por Thiengo et al. (2010), encontrou-se que pessoas com rede de apoio social pequena e menos recíprocas estão mais sujeitas a sofrer com algum tipo de transtorno mental, como a depressão.

Finalizando, cabe, ainda, ressaltar a importância de novos estudos que esclareçam melhor acerca do apoio no contexto da depressão pós-parto e até mesmo a ilustrando na conjuntura adolescente, para viabilizar intervenções adequadas que promovam o bem-estar psíquico da mãe, assim como do novo bebê. Baptista (2006) enfatizou a importância de conhecer fatores que possam evitar ou amortecer os eventos estressantes relacionados com gravidez e puerpério, como por exemplo, o apoio social, a fim de se desenvolver estratégias eficazes que sejam capazes de minimizar o impacto de sintomatologias psicológicas/ psiquiátricas como a depressão na relação mãe-bebê, assim como nas relações familiares.

\section{REFERÊNCIAS}

Airosa, S., \& Silva, I. (2013). Associação entre vinculação, ansiedade, depressão, stresse e suporte social na maternidade. Psicologia, Saúde \& Doenças, 14(1), 64-77. Recuperado de http://www.scielo.mec.pt/scielo.php?script=sci_arttext\&pid $=$ S1645-00862013000100005

American Psychiatric Association. (2013). Diagnostic and Statistical Manual of Mental disorders - DSM-5. Washington: American Psychiatric Association.

Angelo, R. C. O., Sabino, L. F., Schwingel, P. A., Lima, A. P. O., Zambaldi, C. F., Cantilino, A., \& Sougey, E. B. (2014). Dor e fatores associados em puérperas deprimidas e não deprimidas. Revista Dor, 15(2), 100-106. doi: /10.5935/18060013.20140022

Arrais, A. R., Mourão, M. A., Fragalle, B. (2014). O pré-natal psicológico como programa de prevenção à depressão pósparto. Saúde e Sociedade, 23(1), 251-264. doi: 10.1590/ S0104-12902014000100020

Baptista, M. N., Baptista, A. S. D., \& Torres, E. C. R. (2006). Associação entre suporte social, depressão e ansiedade em gestantes. Psic: Revista da Vetor Editora, 7(1), 39-48.

Beck, A.T., \& Steer, R.A. (1993). Beck depression inventory. Manual. San Antonio: Psychological Corporation.

Bhandari, S., Bullock, L. F., Bair-Merritt, M., Rose, L., Marcantonio, K., Campbell, J. C., \& Sharps, P. (2012). Pregnant women experiencing IPV: Impact of supportive and non-supportive relationships with their mothers and other supportive adults on perinatal depression: A mixed methods analysis. Issues in Mental Health Nursing, 33(12), 827-837. doi: 10.3109/01612840.2012.712628.

Blos, P. (1996). O segundo processo de individuação na adolescência. Em Transição Adolescente: questões desenvolvimentais (pp. 97-115). Porto Alegre: Artes Médicas.

Bos, S. C., Macedo, A., Marques, M., Pereira, A. T., Maia, B. R., Soares, M. J., ... Azevedo, M. H. (2013). Is positive affect in pregnancy protective of postpartum depression? Revista Brasileira de Psiquiatria, 35(1), 5-12. doi: 10.1016/j. rbp.2011.11.002

Bowlby, J. (1989). Uma base segura - Aplicações clínicas da teoria do apego. (S.M. Barros, Trans.). Porto Alegre, RS: Artes Médicas.

Cabral, S. A., \& Levandowski, D. C. (2011a). Maternal representations of adult mothers: Clinical report using Interview R. Psicologia Clínica, 23(2), 37-52. doi: 10.1590/ S0103-56652011000200004

Cabral, S. A., \& Levandowski, D. C. (2011b). Representações maternas: Teóricos e possibilidades de avaliação e intervenção clínica. Estilos da Clinica, 16(1), 186. doi: 10.11606/issn.19811624.v16i1p186-203
Carter, B., \& McGoldrick, M. (1995). As mudanças no ciclo de vida familiar - Uma estrutura para a terapia familiar (pp. 7-29). Porto Alegre: Artmed.

Cramer, B. G., \& Palacio-Espasa, F. (1993). Técnicas psicoterápicas mãe/bebê. Porto Alegre: Artes Médicas.

Cox, J. L., Holden, J. M., \& Sagovsky, R. (1987). Detection of postnatal depression: Development of the 10-item Edinburgh Postnatal Depression Scale. British Journal of Psychiatry, 150, 782-786. Recuperado de http://www.ncbi.nlm.nih.gov/ pubmed/3651732

Dantas, M. M. C., Araújo, P. C. B., Paulino, D. S., \& Maia, E. M. C. (2012). Avaliação do apoio social e de sintomas depressivos em mães de bebês prematuros hospitalizados. Psicologia em Revista, 18(1), 90-106. doi: 10.5752/P.16789563.2012v18n1p90

Decastro, F., Hinojosa-Ayala, N., \& Hernandez-Prado, B. (2011). Risk and protective factors associated with postnatal depression in Mexican adolescents. Journal of Psychosomatic Obstetrics \& Gynecology, 32(4), 210-217. doi: 10.3109/0167482X.2011.626543

Erikson, E. H. (1998). Adolescência e idade escolar. Em O ciclo de vida completo (pp. 63-67). Porto Alegre: Artmed

Fonseca, V. R. J., da Silva, G. A., \& Otta, E. (2010). Relação entre depressão pós-parto e disponibilidade emocional materna. Cadernos de Saúde Pública, 26(4), 738-746. doi: 10.1590/ S0102-311X2010000400016.

Freitas, A. P. C. O. (2013). Tornar-se avó e a transmissão transgeracional no contexto da maternidade na adolescência (Tese de Doutorado). Universidade Federal do Rio Grande do Sul, Porto Alegre, RS, Brasil.

Golse, B. (2003). Narratividade, filiação e transmissão. São Paulo: Casa do Psicólogo.

Martins, L. W. F. (2014). Aspectos transgeracionais e desenvolvimentais nos modelos de mãe em gestantes adolescentes (Dissertação de mestrado). Universidade Federal do Rio Grande do Sul, Porto Alegre, RS, Brasil.

Martins, L. W. F., Frizzo, G. B., \& Diehl, A. M. P. (2014). A constelação da maternidade na gestação adolescente: Um estudo de casos. Psicologia USP, 25(3), 294-306. doi:10.1590/0103-656420130029

Frizzo, G. B., Brys, I., Lopes, R. D. C. S., \& Piccinini, C. A. (2010). Conjugalidade em contexto de depressão da esposa no final do primeiro ano de vida do bebê. Aletheia, (31), 66-81. Recuperado de http://pepsic.bvsalud.org/scielo.php?script=sci_arttext\&pid $=$ S1413-03942010000100007

Frizzo, G. B., Kahl, M. L. F., \& Oliveira, E. D. (2005). Aspectos psicológicos da gravidez na adolescência. Psico, 36(1), 13-20. Recuperado de http://revistaseletronicas.pucrs.br/revistapsico/ ojs/index.php/revistapsico/article/view/1370 
Frizzo, G. B., \& Piccinini, C. A. (2005). Interação mãe-bebê em contexto de depressão materna: aspectos teóricos e empíricos. Psicologia em Estudo, 10(1), 47-55. doi: 10.1590/ S1413-73722005000100007

Frizzo, G. B., Prado, L. C., Linares, J. L., \& Piccinini, C. A. (2011). Aspectos relacionais da depressão: O conceito de "honorável fachada" em dois casos clínicos. Psicologia Clínica, 23(1), 133-155. doi: 10.1590/S0103-56652011000100009

Goodman, J. H. (2004). Postpartum depression beyond the early postpartum period. Journal of Obstetric, Gynecologic, \& Neonatal Nursing, 33(4), 410-420. doi: $10.1177 / 0884217504266915$.

Kim, T., Connolly, J., \& Tamim, H. (2014). The effect of social support around pregnancy on postpartum depression among Canadian teen mothers and adult mothers in the maternity experiences survey. BMC Pregnancy and Childbirth, 14, 162. doi: 10.1186/1471-2393-14-162.

Klaus, M. H., Kennell, J. H., \& Klaus, P. H. (2000). Vinculo: construindo as bases para um apego seguro e para a independência (M. R. Hofmeister, Trans.). Porto Alegre: Artes Médicas.

Knobel, M. (1981). A síndrome da adolescência normal. In A. Aberastury \& M. Knobel (Eds.), Adolescência normal: um enfoque psicanalítico (pp. 2-4). Porto Alegre: Artes Médicas.

Konradt, C. E., Silva, R. A., Jansen, K., Vianna, D. M., Quevedo, L. A., Souza, L. D. M., Oses, J. P., \& Pinheiro, R. T. (2011). Depressão pós-parto e percepção de suporte social durante a gestação. Revista de Psiquiatria do Rio Grande do Sul, 33(2), 76-79. doi 10.1590/S0101-81082011005000010.

Kreutz, C.M. (2001). A experiência da maternidade e a interação mãe-bebê em mães adolescentes e adultas (Dissertação de mestrado). Universidade Federal do Rio Grande do Sul, Porto Alegre, RS, Brasil.

Laville, C., \& Dionne, J. (1999). A construção do saber. Porto Alegre: Artes Médicas.

Letourneau, N. L., Stewart, M. J., \& Barnfather, A. K. (2004). Adolescent mothers: Support needs, resources, and supporteducation interventions. Journal of Adolescent Health, 35(6), 509-525. doi: 10.1016/j.jadohealth.2004.01.007.

Levandowski, D. C., Piccinini, C. A., \& Lopes, R. C. S. (2009). $\mathrm{O}$ processo de separação-individuação em adolescentes do sexo masculino na transição para a paternidade. Psicologia: Reflexão e Crítica, 22(3), 353-361. doi: 10.1590/S010279722009000300005.

Levandowski, D. C., Barth, B., Munhós, A. A. R., Rödde, A. C., \& Wendland, J. (2012). Apoio familiar e gestação na adolescência: um estudo qualitativo com adolescentes do Vale dos Sinos/BR. Revista Interamericana de Psicologia, 46, 2. Recuperado de http://journals.fcla.edu/ijp/article/view/77088

Linares, J. L., \& Campo, C. (2000). Tras la honorable fachada: Los transtornos depresivos desde una perspectiva relacional. Barcelona: Paidós.

Lopes, R. C. S., Prochnow, L. P., \& Piccinini, C. A. (2010). A relação da mãe com suas figuras de apoio femininas e os sentimentos em relação à maternidade. Psicologia em Estudo, 15(2), 295304. doi:10.1590/S1413-73722010000200008

Malloy-Diniz, L. F., Schlottfeldt, C. G. M. F., Figueira, P., Neves, F. S., \& Corrêa, H. (2010). Escala de Depressão Pós-Parto de Edimburg: Análise fatorial e desenvolvimento de uma versão de seis itens. Revista Brasileira de Psiquiatria, 32(3), 316-318. doi: 10.1590/S1516-44462010000300018

Milgrom, J., \& McCloud, P. (1996). Parenting stress and postnatal depression. Stress Medicine, 12(3), 177-186. doi: 10.1002/(SICI)1099-1700(199607)12:3\%3C177::AIDSMI699\%3E3.0.CO;2-W

Moreira, M. C., \& Sarriera, J. C. (2008). Satisfação e composição da rede de apoio social a gestantes adolescentes. Psicologia em Estudo, 13(4), 781-789. doi: 10.1590/S141373722008000400016

Nonacs, R., \& Cohen, L. S. (2005). Postpartum psychiatric syndromes. In B. J. Sadock \& V. Sadock (Eds.), Kaplan \& Sadock's comprehensive textbook of psychiatry (8th ed., pp. 1276-1283). Philadelphia, PA: Lippincott Williams \& Wilkins.

Núcleo de Infância e Família da Universidade Federal do Rio Grande do Sul. (2008a). Termo de Consentimento Livre e Esclarecido (Instrumento não-publicado). Instituto de Psicologia, Universidade Federal do Rio Grande do Sul, Porto Alegre, RS, Brasil.

Núcleo de Infância e Família da Universidade Federal do Rio Grande do Sul. (2008b) Ficha de dados sócio demográficos da família: versão da mãe (Instrumento não-publicado). Instituto de Psicologia, Universidade Federal do Rio Grande do Sul, Porto Alegre, RS, Brasil.

Núcleo de Infância e Família da Universidade Federal do Rio Grande do Sul. (2009c). Entrevista sobre a maternidade e sobre o desenvolvimento do bebê - terceiro mês de vida do bebê (Instrumento não-publicado). Instituto de Psicologia, Universidade Federal do Rio Grande do Sul, Porto Alegre, RS, Brasil.

Nunes, A. P., \& Phipps, M. G. (2013). Postpartum depression in adolescent and adult mothers: Comparing prenatal risk factors and predictive models. Maternal and Child Health Journal, 17(6), 1071-1079. doi: 10.1007/s10995-012-1089-5.

Piccinini, C. A., Frizzo, G. B., Brys, I., \& Lopes, R. C. S. (2014). Parenthood in the context of maternal depression at the end of the infant's first year of life. Estudos de Psicologia (Campinas), 31(2), 203-214. doi 10.1590/0103166X2014000200006.

Piccinini, C. A., Rapoport, A., Levandowski, D. C., \& Voigt, P. R. (2002). Apoio social percebido por mães adolescentes e adultas: da gestação ao terceiro mês de vida do bebê. Psico (Porto Alegre), 33(1), 9-35. doi: 10.1590/S1413-81232011000500028.

Prochnow, L. P., \& Lopes, R. D. C. S. (2007). A relação da mãe em situação de depressão com suas figuras femininas de apoio. Psico, 38(3), 285-291. Recuperado de http:// revistaseletronicas.pucrs.br/ojs/index.php/revistapsico/article/ viewFile/2889/2184

Rapoport, A. (2003). Da gestação ao primeiro ano de vida do bebê: Apoio social e o ingresso na creche (Tese de doutorado). Universidade Federal do Rio Grande do Sul, Porto Alegre, RS, Brasil.

Rapoport, A., \& Piccinini, C. A. (2006). Apoio social e experiência da maternidade. Revista Brasileira de Crescimento e Desenvolvimento Humano, 16(1), 85-96. Recuperado de http://pepsic.bvsalud.org/scielo.php?script=sci_arttext\&pid $=$ S0104-12822006000100009

Rapoport, A., \& Piccinini, C. A. (2011). Maternidade e situações estressantes no primeiro ano de vida do bebê. Psico USF, 16(2), 215-225. doi: 10.1590/S1413-82712011000200010.

Santos, I. S., Matijasevich, A., Tavares, B. F., Barros, A. J. D., Botelho, I. P., Lapolli, C., ... Barros, F.C. (2007). Validation of the Edinburgh Postnatal Depression Scale (EPDS) in a sample of mothers from the 2004 Pelotas Birth Cohort Study. Cadernos de Saúde Pública, 23(11), 2577-2588. doi 10.1590/S0102311X2007001100005.

Schwartz, T., Vieira, R., \& Geib, L. T. C. (2011). Apoio social a gestantes adolescentes: Desvelando percepções. Ciência \& Saúde Coletiva, 16(5), 2575-2585. doi: 10.1590/S141381232011000500028.

Schwengber, D. D. S, \& Piccinini, C. A. (2005). A Experiência da maternidade no contexto da depressão materna no final do primeiro ano de vida do bebê. Estudos de Psicologia (Campinas), 22, 143-146. doi: 10.1590/S0103-166X2005000200004. 
Stern, D. (1997). A constelação da maternidade: o panorama da psicoterapia pais-bebê (M.V.A. Veronese, Trans.). Porto Alegre: Artes Médicas.

Thiengo, D. L., Santos, J. F. C., Mason, V. C., Abelha, L., \& Lovisi, G. M. (2011). Associação entre apoio social e depressão durante a gestação: uma revisão sistemática. Cadernos de Saúde Coletiva, 19(2),129-138. Recuperado de http://www.iesc.ufrj.br/cadernos/images/csc/2011_2/artigos/ csc_v19n2_129-138
Toomey, R. B., Umaña-Taylor, A. J., Jahromi, L. B., \& Updegraff, K.A. (2013). Measuring social support from mother figures in the transition from pregnancy to parenthood among mexicanorigin adolescent mothers. Hispanic Journal of Behavioral Sciences, 35(2), 194-212. doi: 10.1177/0739986312470636.

Winnicott, D. W. (1985). E o pai? In D. W. Winnicott (Ed.), $A$ criança e o seu mundo (pp. 127-133). Rio de Janeiro: Zahar.

Yin, R.K.(2001). Estudo de caso-Planejamento e métodos (2 $\left.2^{\mathrm{a}} \mathrm{ed}.\right)$. Porto Alegre: Bookman. 